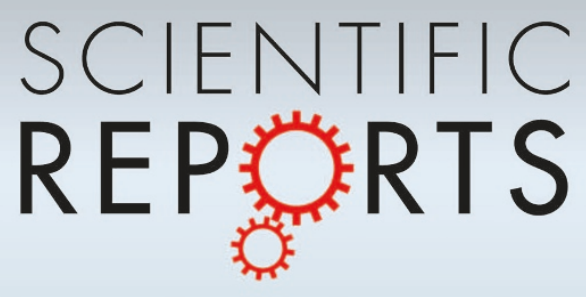

OPEN

SUBJECT AREAS:

ELECTRONIC STRUCTURE

DENSITY FUNCTIONAL THEORY

TWO-DIMENSIONAL MATERIALS

Received

13 March 2014

Accepted

6 June 2014

Published

25 June 2014

Correspondence and requests for materials should be addressed to X.W. (xiwu@ustc.edu.

cn) or W.Z.

(whhzhang@ustc.edu.

cn)

\section{A Theoretical Study of Single-Atom Catalysis of CO Oxidation Using Au Embedded 2D h-BN Monolayer: A CO-Promoted $\mathrm{O}_{2}$ Activation}

\author{
Keke Mao ${ }^{1,2}$, Lei Li ${ }^{4}$, Wenhua Zhang ${ }^{1,3}$, Yong Pei ${ }^{5}$, Xiao Cheng Zeng ${ }^{4}$, Xiaojun Wu $\mathrm{U}^{1,2,3}$ \& Jinlong Yang ${ }^{2,3}$
}

\begin{abstract}
${ }^{1}$ Key Lab of Materials for Energy Conversion, Department of Materials Science and Engineering, University of Science and Technology of China, Hefei, Anhui 230026, China, ${ }^{2}$ Hefei National Lab for Physical Sciences at Microscale, University of Science and Technology of China, Hefei, Anhui 230026, China, ${ }^{3}$ Synergetic Innovation Center of Quantum Information \& Quantum Physics, University of Science and Technology of China, Hefei, Anhui 230026, China, ${ }^{4}$ Department of Chemistry and Department Mechanics and Materials Engineering, University of Nebraska-Lincoln, Lincoln, NE 68588, USA, ${ }^{5}$ Department of Chemistry, Xiangtan University, Hunan 411105 , China.
\end{abstract}

The $\mathrm{CO}$ oxidation behaviors on single $\mathrm{Au}$ atom embedded in two-dimensional $\boldsymbol{h}$ - $\mathrm{BN}$ monolayer are investigated on the basis of first-principles calculations, quantum Born-Oppenheim molecular dynamic simulations (BOMD) and micro-kinetic analysis. We show that $\mathrm{CO}$ oxidation on $h$-BN monolayer support single gold atom prefers an unreported tri-molecular Eley-Rideal (E-R) reaction, where $\mathrm{O}_{2}$ molecule is activated by two pre-adsorbed CO molecules. The formed OCOAuOCO intermediate dissociates into two $\mathrm{CO}_{2}$ molecules synchronously, which is the rate-limiting step with an energy barrier of $0.47 \mathrm{eV}$. By using the micro-kinetic analysis, the $\mathrm{CO}$ oxidation following the tri-molecular E-R reaction pathway entails much higher reaction rate $\left(1.43 \times 10^{5} \mathrm{~s}^{-1}\right)$ than that of bimolecular Langmuir-Hinshelwood (L-H) pathway $\left(4.29 \mathrm{~s}^{-1}\right)$. Further, the quantum BOMD simulation at the temperature of $300 \mathrm{~K}$ demonstrates the complete reaction process in real time.

ingle atomic metal catalyst anchored to support has become attractive partly for the maximum usage of noble metal atom and great potential to achieve high activity and selectivity ${ }^{1}$. In experiment, the high surface free energy of metal atom is one key issue, which usually induces an aggregation of metal atoms into big cluster on support. In the past decades, appropriate metal oxide supports, which have strong interaction with metal atom, have been selected and several techniques have been developed to achieve supported single metal atom for catalysis ${ }^{2-5}$. Meanwhile, the decreased freedom of catalyst in supported single metal atom materials makes it possible for theoretical understanding their catalytic behaviours.

In recent years, two-dimensional monolayer materials, such as graphene, have been used as promising catalyst supports for their large specific surface areas, novel electronic and thermal properties, and close contact with catalysts, which may play an important role in activity enhancement of catalysts ${ }^{6-20}$. To achieve atomically dispersed metal on graphene, various vacancy defects have been introduced into carbon network of graphene, strengthening the interaction between the metal atom and graphene. Both theoretical and experimental works have indicated that the single metal atom supported by defective graphene present enhanced catalysis, for instance the $\mathrm{CO}$ oxidation and oxygen reduction reaction on $\mathrm{Au}, \mathrm{Cu}, \mathrm{Fe}, \mathrm{Pt}$, and $\mathrm{Nb}$ supported by graphene $\mathrm{e}^{21-26}$. However, the thermal stability and chemical reactivity issues associated graphene may hinder its application. Alternatively, the $h$-BN monolayer is a structural analogue to graphene, but exhibits quite different properties ${ }^{27-31}$. It is well known that $h$-BN monolayer is a wide band gap semiconductor with high chemical and thermal stability. Moreover, boron vacancy defect can be prepared by electron bombardment method ${ }^{32,33}$ and single metal atom can be deposited by mass-selected soft-landing techniques, improved wet chemistry method, or atomic layer deposition method, as that on grahene and other substrates ${ }^{2,5,21,25}$. The high ionicity of B-N bonds and possible vacancy defects in $h$-BN monolayer present great opportunity to modify the catalytic activity of supported single metal atom catalyst, even superior to graphene. Recently, Fe and Au atom supported by $h$-BN monolayer have been predicted theoretically as a single metal catalysis for $\mathrm{CO}$ oxidation ${ }^{34-36}$. 

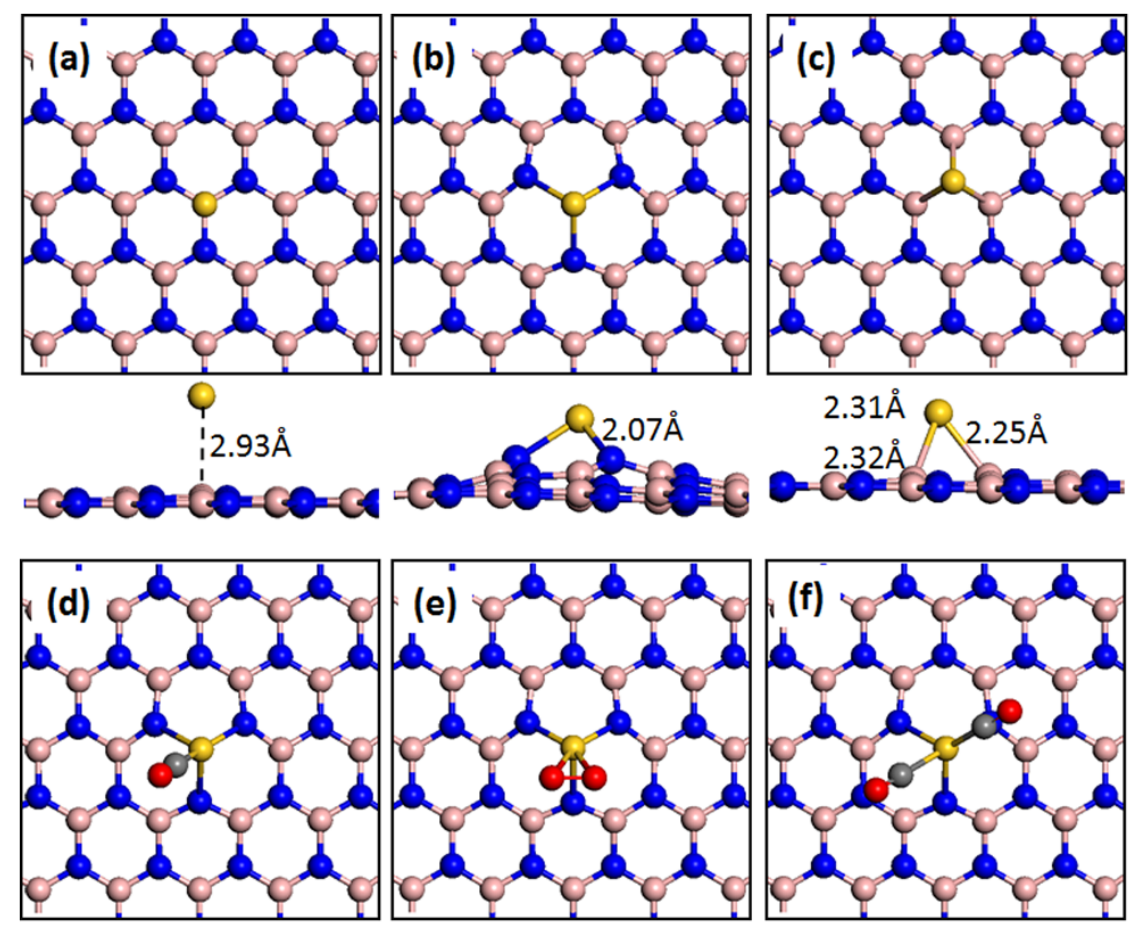

Figure 1 Optimized structures of Au adsorbed and embedded $\boldsymbol{h}$-BN monolayer. The optimized structures of Au atom on a) perfect and defective $h$-BN monolayer with either b) B vacancy or c) $\mathrm{N}$ vacancy are displayed from both the top and side views, respectively. $\mathrm{d}$ ) to f) display the lowest energy structure of $\mathrm{CO}, \mathrm{O}_{2}$, and two $\mathrm{CO}$ molecules on $\mathrm{Au} / \mathrm{V}_{\mathrm{B}}-h-\mathrm{BN}$. The pink, blue, red, grey and yellow spheres represent $\mathrm{B}, \mathrm{N}, \mathrm{O}, \mathrm{C}$ and Au, respectively.

$\mathrm{CO}$ oxidation on gold nanostructures at low temperature has been intensively investigated for both advancing fundamental chemistry and industrial applications, including bare and oxide supported single atom, clusters, one- and two-dimensional structures $^{6,19,37-55}$. In these gold-based CO oxidation catalysis reaction, either gold nanostructure itself (in gas phase) or the perimeter interface between the gold nanostructure and oxide support provides active sites for the $\mathrm{O}_{2}$ activation via bimolecular LangmuirHinshelwood (L-H) mechanism, Eley-Rideal (E-R) mechanism, or both of them ${ }^{55}$. A tri-molecular L-H mechanism has also been proposed recently when triangular Au sites are available on surface of gold clusters, where the $\mathrm{O}_{2}$ activation is promoted by $\mathrm{CO}$ molecules adsorbed on the gold clusters ${ }^{56}$. The suggested factors that are responsible for high catalytic activity includes quantum size effect, structural effect of low-coordinated Au sites, strain of gold, charging effect, or combined effect of the oxide support and gold nanostructures $\mathrm{s}^{6,43,47-51}$

In this work, on the basis of first-principles calculations and quantum Born-Oppenheim molecular dynamic (BOMD) simulation, an unreported $\mathrm{CO}$-promoted $\mathrm{O}_{2}$ activation and tri-molecular E-R CO oxidation are firstly discovered on atomic gold supported by $h$ - $\mathrm{BN}$ monolayer with boron vacancy (B vacancy). $\mathrm{O}_{2}$ is activated by two adsorbed $\mathrm{CO}$ molecules, and the formed OCOAuOCO intermediate dissociates into two $\mathrm{CO}_{2}$ molecules synchronously with an energy barrier of $0.47 \mathrm{eV}$, which is the rate-limiting step. Compared with bimolecular L-H mechanism, the trimolecular E-R mechanism presents a reduced energy barrier for $\mathrm{CO}$ oxidation. In contrast, $\mathrm{Au}$ atom adsorbed on the $\mathrm{N}$ vacancy defect will be displaced by $\mathrm{O}_{2}$ molecule. The estimated $\mathrm{CO}$ oxidation rate following the trimolecular E-R mechanism exhibit a high value of $1.43 \times 10^{5} \mathrm{~s}^{-1}$. The quantum BOMD simulation at the temperature of $300 \mathrm{~K}$ reproduces the entire reaction process.

\section{Results and discussion}

We firstly examined the adsorption of a single $\mathrm{Au}$ atom on the pristine and defective $h$-BN monolayer with either $\mathrm{N}$ or B vacancy defect, denoted as $\mathrm{Au} / h-\mathrm{BN}, \mathrm{Au} / \mathrm{V}_{\mathrm{N}}-h-\mathrm{BN}$, and $\mathrm{Au} / \mathrm{V}_{\mathrm{B}}-h-\mathrm{BN}$. The optimized structures are plotted in Figure 1 . For the perfect $h-\mathrm{BN}$ sheet, $\mathrm{Au}$ atom prefers to adsorb on the top site of either $\mathrm{N}$ or $\mathrm{B}$ atoms with the adsorption energies of 0.10 and $0.11 \mathrm{eV}$, respectively. The distance between $\mathrm{Au}$ and $\mathrm{N}$ atom is as large as $2.93 \AA$, as shown in Figure 1a. Similar distance value can be found for the adsorption on the top site of $\mathrm{B}$ atom. The weak interaction between $\mathrm{Au}$ atom and perfect $h$-BN sheet suggests that the adsorbed $\mathrm{Au}$ atoms may be clustering or easily desorbed from the $h$-BN sheet. Thus, a single $\mathrm{Au}$ atom supported by perfect $h$-BN sheet is not practicable for catalysis applications at room temperature. In contrary, a single $\mathrm{Au}$ atom can be anchored on the vacancy defect of $h$-BN sheet with short $\mathrm{Au}-\mathrm{N}$ or $\mathrm{Au}-\mathrm{B}$ bond. As shown in Figure $1 \mathrm{~b}$ and $1 \mathrm{c}$, the shortest Au$\mathrm{N}$ and $\mathrm{Au}-\mathrm{B}$ bond lengths are 2.07 and $2.25 \AA$ for boron and nitrogen vacancy defect, respectively. The calculated adsorption energies of $\mathrm{Au}$ on $\mathrm{V}_{\mathrm{N}}-h$-BN and $\mathrm{V}_{\mathrm{B}}-h$-BN sheets indicate that $\mathrm{Au}$ atom can bind strongly with the adsorption energy of 3.17 and $3.45 \mathrm{eV}$, respectively. These values are comparable to the average cohesive energy of $\mathrm{Au}$ bulk (3.78 eV per atom $)^{57}$, indicating that a well distribution of single $\mathrm{Au}$ atom in the vacancy defect of $h$-BN sheet is achievable in experiment. The $\mathrm{Au} / \mathrm{V}_{\mathrm{B}}-h-\mathrm{BN}$ is ferromagnetic with a total magnetic moment of $2 \mu \mathrm{B}$ per supercell. The spin charge density mainly distribute on the nitrogen atoms at the vacancy defect and the adsorbed $\mathrm{Au}$ atom. On the contrary, the $\mathrm{Au} / \mathrm{V}_{\mathrm{N}}-h-\mathrm{BN}$ is nonmagnetic. By placing $\mathrm{Au}$ atom in the vacancy defect, about 0.10 and 0.46 charges are transferred from Au to the defective $h$-BN sheet with nitrogen and boron defect based on Hirshfeld charge analysis respectively.

Although Au binds to the defective $h$-BN monolayer strongly, it is still necessary to investigate the thermal stability of single Au atom on the defect in the reaction, i.e. the adsorption competition between the gas molecules ( $\mathrm{CO}$ and $\mathrm{O}_{2}$ molecule) and $\mathrm{Au}$ atom on the vacancy defect of $h$-BN sheet. In an attempt to answer this question, we examined the adsorption energy of $\mathrm{CO}$ and $\mathrm{O}_{2}$ molecule on the defective $h$-BN monolayer. Various adsorption configurations have been considered (See Supporting Information Figure S1), where the largest adsorption energies are 8.81 and $1.75 \mathrm{eV}$ for $\mathrm{O}_{2}$ on the $\mathrm{V}_{\mathrm{N}^{-}} h^{-}$ 


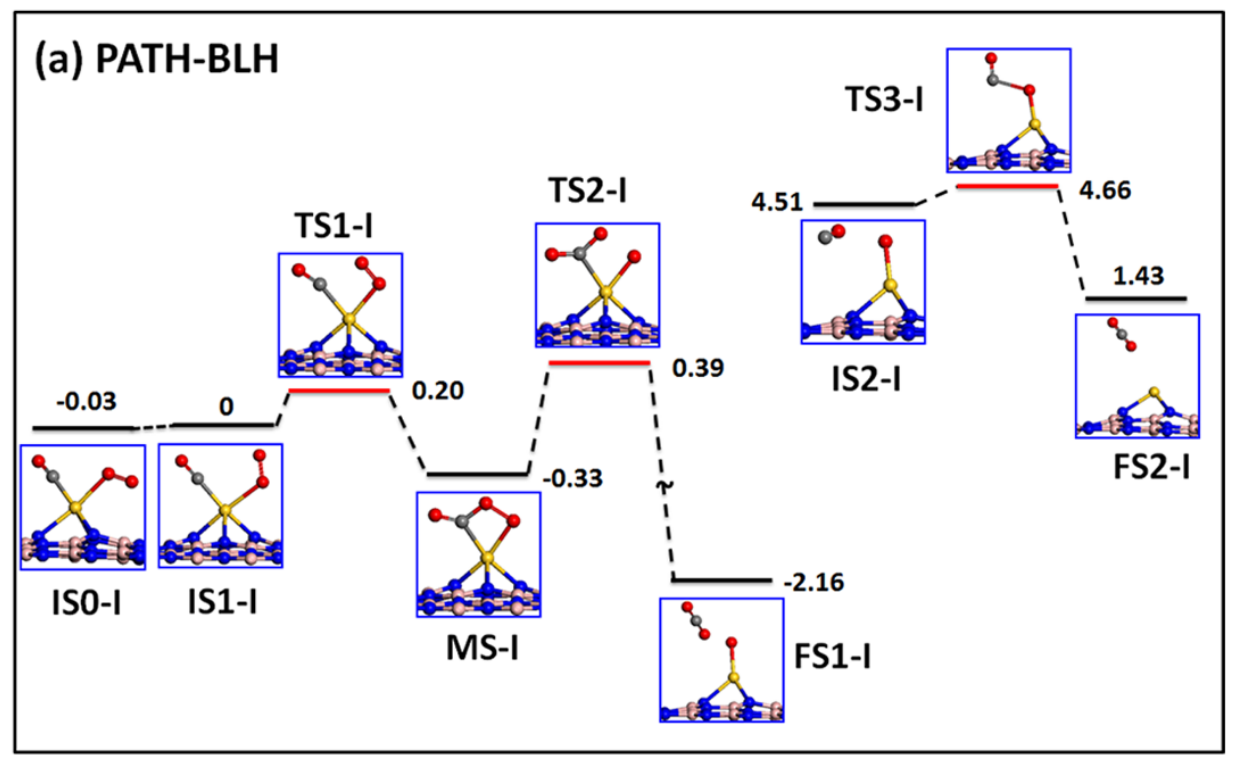

(b) PATH-TER

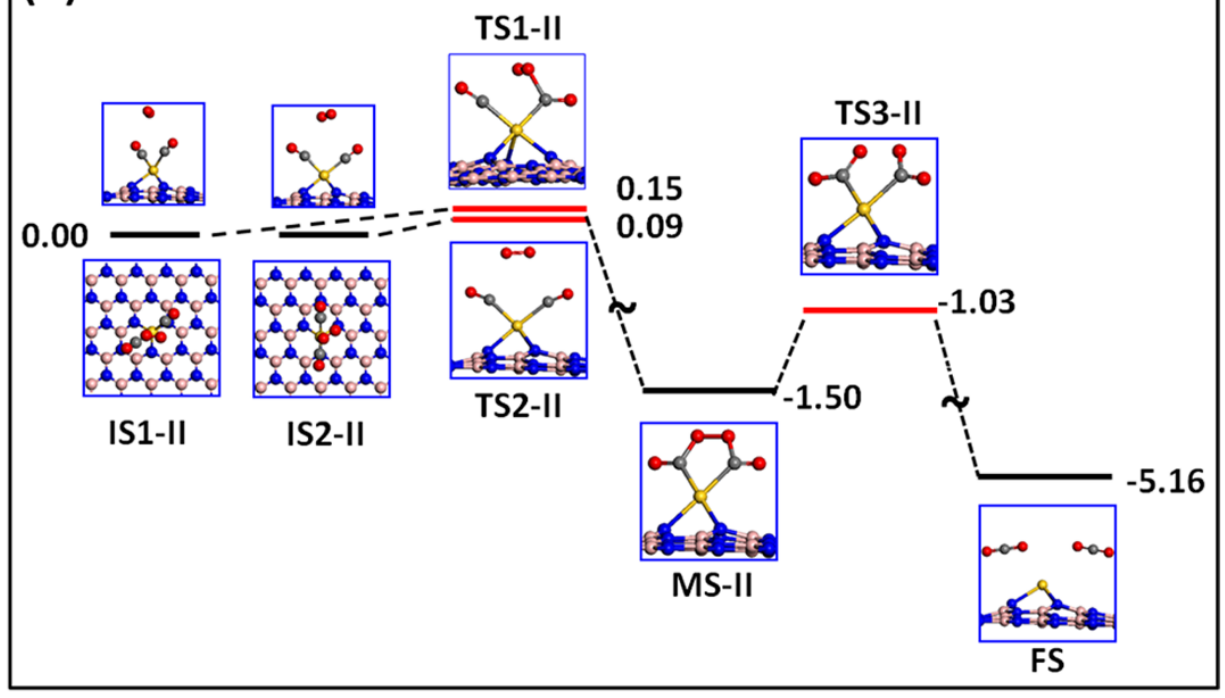

Figure $2 \mid$ Reaction pathways of CO on Au-embedded $h$-BN monolayer. (a) CO oxidation follows a bimolecular L-H mechanism. (b) CO oxidation follows a tri-molecular E-R mechanism All energies are given with respect to coadsorbed CO molecules on $\mathrm{Au} / \mathrm{V}_{\mathrm{B}}-\mathrm{h}-\mathrm{BN}$.

$\mathrm{BN}$ and $\mathrm{V}_{\mathrm{B}}-h-\mathrm{BN}$, respectively. For $\mathrm{CO}$ molecule, the values are 3.97 and $5.86 \mathrm{eV}$ for $\mathrm{V}_{\mathrm{N}}-h-\mathrm{BN}$ and $\mathrm{V}_{\mathrm{B}}-h-\mathrm{BN}$, respectively. The large adsorption energy difference between the $\mathrm{O}_{2}$ molecule $(8.81 \mathrm{eV})$ and $\mathrm{Au}$ atom $(3.17 \mathrm{eV})$ on $\mathrm{V}_{\mathrm{N}}-h-\mathrm{BN}$ implies that the adsorbed $\mathrm{Au}$ atom may be easily displaced when $\mathrm{O}_{2}$ molecule presents. The firstprinciple based $\mathrm{BOMD}$ simulation at $300 \mathrm{~K}$ confirms this view (Movies S1 and S2 in Supporting Information). During 5 ps simulation times, the $\mathrm{O}_{2}$ molecule in gas phase displaces the adsorbed $\mathrm{Au}$ atom from $\mathrm{V}_{\mathrm{N}}-h-\mathrm{BN}$ and occupies the defect, whereas $\mathrm{Au} / \mathrm{V}_{\mathrm{B}}-h-\mathrm{BN}$ system is stable for $\mathrm{CO}$ and $\mathrm{O}_{2}$ in the simulation time scale. Interestingly, the $\mathrm{B}$ vacancy defects in $h$ - $\mathrm{BN}$ monolayer are found to be preferably formed in experiment by electron bombardment and theoretical calculation predicts that in $\mathrm{N}$-rich environment $\mathrm{B}$ vacancy is more stable than $\mathrm{N}$ vacancy ${ }^{32}$, suggesting the single atomic gold supported by $h$-BN sheet with boron vacancy defect is practicable for $\mathrm{CO}$ oxidation.

In the following section, we only examined the $\mathrm{CO}$ oxidation process on single atomic Au supported by $h$-BN monolayer containing B-vacancy defect. Figure $1 \mathrm{~d}$ and 1e display the most stable structures of $\mathrm{CO}$ and $\mathrm{O}_{2}$ molecule on $\mathrm{Au}$ atom. Different adsorption configurations and corresponding adsorption energies are summarized in Figure S2 (See Supporting Information). CO molecule is adsorbed on the $\mathrm{Au}$ atom with a tilted $\mathrm{C}$-Au bond, and $\mathrm{O}_{2}$ molecule forms peroxide structure with elongated O-O distance of $1.33 \AA$. The adsorption energy of $\mathrm{CO}$ molecule $(1.28 \mathrm{eV})$ on $\mathrm{Au} / \mathrm{V}_{\mathrm{B}}-h-\mathrm{BN}$ is distinctly larger than that of $\mathrm{O}_{2}(0.78 \mathrm{eV})$, implying that the adsorption of $\mathrm{CO}$ is energetically preferred. When $\mathrm{CO}$ presents on $\mathrm{Au}$, the adsorption energy of $\mathrm{O}_{2}$ on $\mathrm{Au} / \mathrm{V}_{\mathrm{B}}-h-\mathrm{BN}$ is only $0.08 \mathrm{eV}$, whereas the adsorption energy of the second $\mathrm{CO}$ molecule is $0.22 \mathrm{eV}$ without including van der Waals (vdW) interaction correction. Test calculations with vdW correction also confirm this conclusion. Considering the vdW correction, these values are 0.40 and $0.18 \mathrm{eV}$, respectively. Thus, two $\mathrm{CO}$ molecules prefer to be adsorbed on a single atomic $\mathrm{Au}$ supported by defective $h$-BN monolayer with an average energy of $0.75 \mathrm{eV}$ per $\mathrm{CO}$ molecule, forming a $\mathrm{V}$-shape $\mathrm{O}-\mathrm{C}-\mathrm{Au}-\mathrm{C}-\mathrm{O}$ structure, as shown in Figure 1f. The adsorption of two CO molecules on supported Au largely results from the charge states of gold, where the gold atom still possesses +0.41 e charge with one $\mathrm{CO}$ adsorbed. Note that the adsorption of $\mathrm{CO}$ molecules on Au doesn't weaken the interaction between $\mathrm{Au}$ atom and the $h$-BN monolayer with boron vacancy 

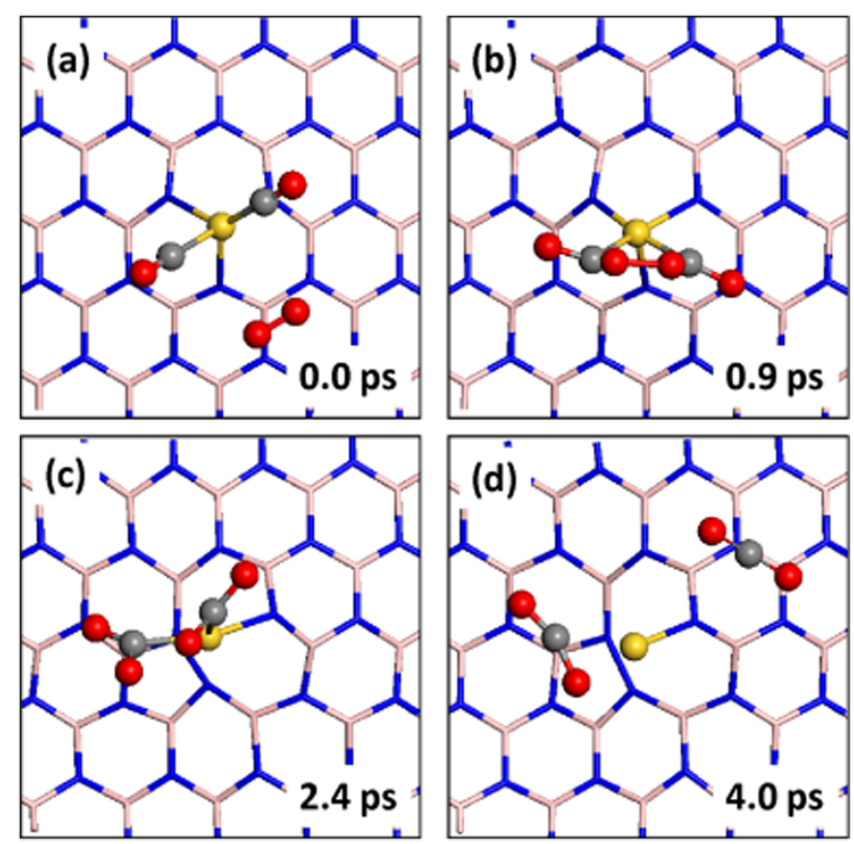

Figure 3 BOMD simulation of CO oxidation on Au-embedded $h$-BN monolayer. The snapshots at $0.0,0.9,2.4$ and 4.0 ps of BOMD simulation of $\mathrm{CO}$ oxidation on $\mathrm{Au} / \mathrm{V}_{\mathrm{B}}-h-\mathrm{BN}$ are displayed. The pink, blue, red, grey and yellow spheres represent $\mathrm{B}, \mathrm{N}, \mathrm{O}, \mathrm{C}$ and $\mathrm{Au}$, respectively.

defect. The calculated adsorption energy of AuCO and $\mathrm{Au}(\mathrm{CO})_{2}$ species with $\mathrm{V}_{\mathrm{B}}-h-\mathrm{BN}$ monolayer are 4.00 and $3.22 \mathrm{eV}$, respectively, which are similar with that of $\mathrm{Au}$ atom on $\mathrm{V}_{\mathrm{B}}-h-\mathrm{BN}$ monolayer $(3.45 \mathrm{eV})$. Thus, the single atomic catalyst of $\mathrm{Au} / \mathrm{V}_{\mathrm{B}}-h-\mathrm{BN}$ is thermally stable even during the $\mathrm{CO}$ oxidation process. The calculated energy barrier of $\mathrm{CO}$ molecule kicking off $\mathrm{Au}(\mathrm{CO})_{2}$ specie from $\mathrm{V}_{\mathrm{B}}-h$ $\mathrm{BN}$ is about $1.37 \mathrm{eV}$, which confirming the stability of the catalyst.

Further, we explore the possible reaction pathways of CO oxidation on the single atomic Au catalyst anchored to the B vacancy of $h$ BN sheet. Very recently, Gao et al. investigated the $\mathrm{O}_{2}$ activation and $\mathrm{CO}$ oxidation on $h$-BN surface supported gold atom and dimer by using density functional theory ${ }^{35}$. They proposed that the $h$-BN surface is not inert to gold nanoparticles and the $\mathrm{CO}$ oxidation can proceed via either a two-step pathway, i.e. two $\mathrm{CO}_{2}$ molecules are formed independently, or a self-promotion pathway on a nitrogen vacancy ( $\mathrm{N}$ vacancy), following the bimolecular $\mathrm{L}-\mathrm{H}$ mechanism ${ }^{35}$. At first, the traditional bimolecular L-H mechanism is examined in our calculations (PATH-BLH), as shown Figure 2a. The energy of initial structure (IS) is set as zero. After one CO molecule is adsorbed on $\mathrm{Au} / \mathrm{V}_{\mathrm{B}}-h-\mathrm{BN}, \mathrm{O}_{2}$ molecule attaches to the $\mathrm{Au}$ atom to form OCOO intermediate (MS-I in PATH-BLH) with an energy barrier of $0.23 \mathrm{eV}$. The OCOO intermediate dissociates into $\mathrm{CO}_{2}$ and an adsorbed $\mathrm{O}$ atom with an energy barrier of $0.72 \mathrm{eV}$ (TS2-I). Further, the adsorbed $\mathrm{O}$ atom and gas $\mathrm{CO}$ molecule forms a $\mathrm{CO}_{2}$ molecule with an energy barrier of $0.15 \mathrm{eV}$ (TS3-I). However, as the adsorption energy of second $\mathrm{CO}$ on the $\mathrm{CO}$ pre-adsorbed $\mathrm{Au} / \mathrm{V}_{\mathrm{B}}-h-\mathrm{BN}$ $(0.22 \mathrm{eV})$ is larger than that of $\mathrm{O}_{2}$ molecule $(0.08 \mathrm{eV})$, the population of $\mathrm{CO}-\mathrm{O}_{2}$ co-adsorbed configuration $\left(\mathrm{f}_{\mathrm{CO}-\mathrm{O} 2}\right)$ is almost two orders less than that of $\mathrm{CO}-\mathrm{CO}$ co-adsorbed configuration $\left(\mathrm{f}_{\mathrm{CO}-\mathrm{CO}}\right)$, which can be estimated as $\mathrm{f}_{\mathrm{CO}-\mathrm{O} 2} / \mathrm{f}_{\mathrm{CO}-\mathrm{CO}}=\exp (-\Delta E / R T)$ with $\Delta \mathrm{E}=0.14 \mathrm{eV}$ at room temperature $(\mathrm{T}=293 \mathrm{~K})$. Thus, the process via PATH-BLH may play a minor role in $\mathrm{CO}$ oxidation.

In the following, the possible reaction among two adsorbed $\mathrm{CO}$ molecules and gas $\mathrm{O}_{2}$ molecule is investigated. Note that the gas phase $\mathrm{O}_{2}$ molecule travels in a spin-triplet configuration up to the distance close to the surface where hybridization becomes significant $^{58}$ and the adiabatic theory where its spin state continuously changes as it approaches the surface can result in an artificially small barrier for $\mathrm{O}_{2}$ dissociation. To overcome this problem, in our calculations, the whole system is fixed at triplet state to provide reliable energy barriers for the $\mathrm{O}_{2}$ activation process, which has been adopted in similar simulations previously ${ }^{57}$. In other reaction process, the spin states of whole system are fully relaxed to obtain the minimum energy reaction pathway.

Figure $2 \mathrm{~b}$ displays the reaction pathway of gas $\mathrm{O}_{2}$ molecule to two adsorbed $\mathrm{CO}$ molecules on $\mathrm{Au} / \mathrm{V}_{\mathrm{B}}-h-\mathrm{BN}$. Different from PATH$\mathrm{BLH}$, as two $\mathrm{CO}$ molecules co-adsorb on $\mathrm{Au} / \mathrm{V}_{\mathrm{B}}-h-\mathrm{BN}, \mathrm{O}_{2}$ activation prefers an unreported tri-molecular E-R mechanism (PATH-TER), i.e. $\mathrm{O}_{2}$ molecule is activated by $\mathrm{CO}$ molecules directly. Two paths with comparable energy barriers are found for the $\mathrm{O}_{2}$ molecule approaching $\mathrm{CO}$ molecules as shown in Figure 2b. In the transition state of the first pathway (TS1-II), $\mathrm{O}_{2}$ molecule approaches one $\mathrm{CO}$ molecule with the nearest $\mathrm{C}-\mathrm{O}$ distance of about $1.65 \AA$ and O-O bond length of $1.31 \AA$. The energy barrier is about $0.15 \mathrm{eV}$. In TS2-II structure, however, $\mathrm{O}_{2}$ molecule approaches two $\mathrm{C}$ atoms simultaneously with a relative low energy barrier of about $0.09 \mathrm{eV}$. The distance between $\mathrm{C}$ atoms and $\mathrm{O}_{2}$ molecule ranges from 2.68 to $2.79 \AA$ and O-O distance is about $1.24 \AA$. The energy barriers in these two pathways are relatively lower than that in PATH-BLH $(0.20 \mathrm{eV})$. All the structures of IS1-II, IS2-II, TS1-II, TS2-II, MS-II in the first step are in the triplet states, both reaction paths precede on triplet potential energy surface. Both reaction paths lead to the formation of OOCAuCOO* intermediate $(-1.50 \mathrm{eV})$ with pentagonal ring structure (MS), where O-O distance is elongated to $1.49 \AA$. Next, OOCAuCOO* intermediate dissociates to form two $\mathrm{CO}_{2}$ molecules via TS2. The O-O distance is $1.90 \AA$ and the energy barrier is $0.47 \mathrm{eV}$. The dissociation of OOCAuCOO intermediate is the rate-limiting step in whole reaction. The frequency calculations are performed to confirm the searched transition structures (See Supporting Information Figure S3). Also, the information about charge transfer and magnetic moment of whole system are summarized in Table S1 (See Supporting Information).

To visualize the complete reaction in real-time, we performed a first-principles based BOMD simulations at the temperature of $300 \mathrm{~K}$ to investigate the $\mathrm{CO}$ oxidation on $\mathrm{Au} / \mathrm{V}_{\mathrm{B}}-h$-BN (Move $\mathrm{S} 2$ in Supporting Information). The total simulation time is $5 p s$, where the entire reaction process is reproduced. Figure 3 displays the snapshots of structure at $0.0,0.9,2.4$, and $4.0 \mathrm{ps}$. Initially, the distance between $\mathrm{O}_{2}$ and adsorbed CO molecule is longer than $5.0 \AA$. With the time elapses, $\mathrm{O}_{2}$ molecule approaches to the adsorbed $\mathrm{CO}$ molecules and OOCAuCOO intermediate forms at about 0.9 ps. At about $2.4 \mathrm{ps}$, $\mathrm{O}-\mathrm{O}$ bond breaks up and two $\mathrm{CO}_{2}$ molecules are observed at about $4.0 \mathrm{ps}$, where one $\mathrm{CO}_{2}$ molecule is in gas phase and the other one weakly binds to $\mathrm{Au}$ atom. A structural optimization on this structure reveals that two $\mathrm{CO}_{2}$ molecules escape spontaneously and $\mathrm{Au} / \mathrm{VB}-\mathrm{h}-\mathrm{BN}$ restores its original structure. Moreover, a BOMD simulation with four $\mathrm{CO}$ and two $\mathrm{O}_{2}$ molecules in gas phase also reproduces this process (See Movie S3 in Supporting Information).

On the basis of micro-kinetics method (See details in Supporting Information), the maximum reaction rates for PATH-BLH and PATH-TER are calculated to investigate the favorability of two reaction pathways. CO oxidation following the tri-molecular E-R mechanism entails much higher reaction rate $\left(1.43 \times 10^{5} \mathrm{~s}^{-1}\right)$ than that of bimolecular L-H mechanism $\left(4.29 \mathrm{~s}^{-1}\right)$, which again confirms that the tri-molecular E-R mechanism is more favourable for $\mathrm{CO}$ oxidation in the $\mathrm{Au} / \mathrm{V}_{\mathrm{B}}-h$-BN system. In PATH-BLH, the reaction rate is mainly limited by the extreme small adsorption energy of $\mathrm{O}_{2}$ molecule and the high reaction barrier $(0.72 \mathrm{eV})$ for TS2-II in Figure 2a. However, in the PATH-TER, the promoting effect of co-adsorbed $\mathrm{CO}$ molecules enables the formation of $\mathrm{CO}_{2}$ with much lower reaction barrier $(0.47 \mathrm{eV})$.

Alternatively, the third pathway (PATH-III) may be possible based on PATH-BLH, demonstrated in Figure S3 (See Supporting 
(a)
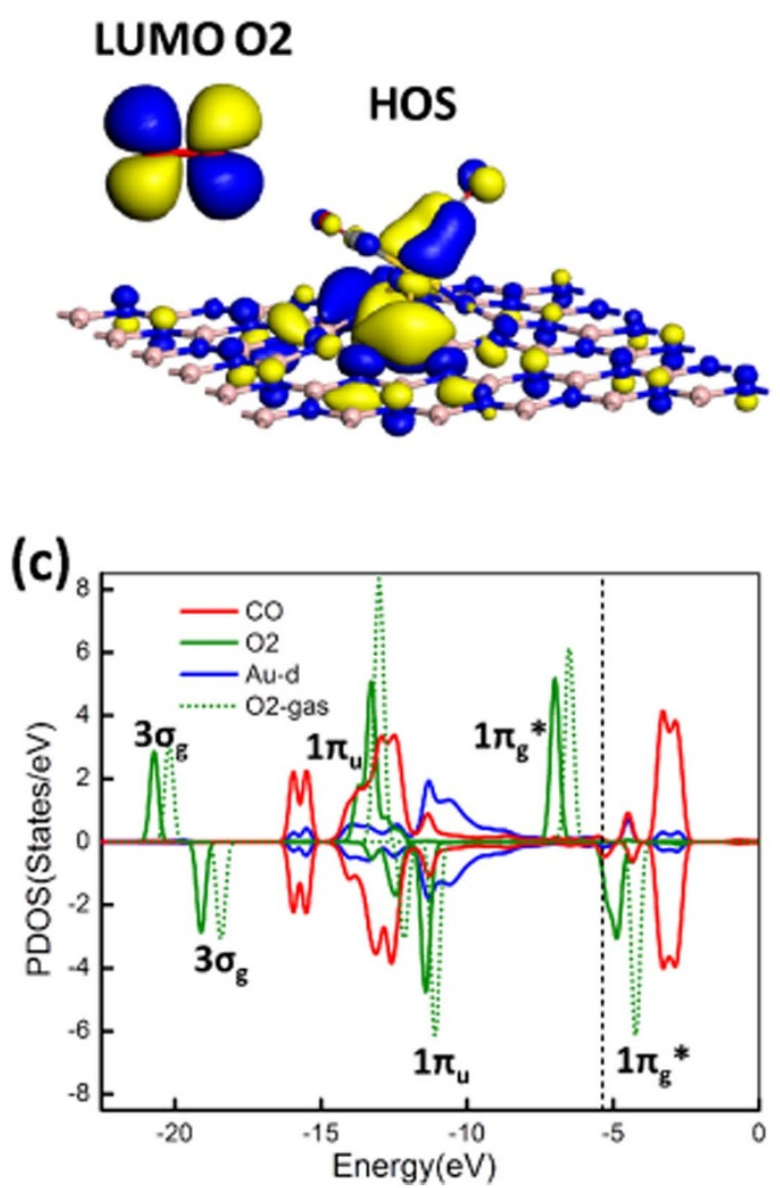

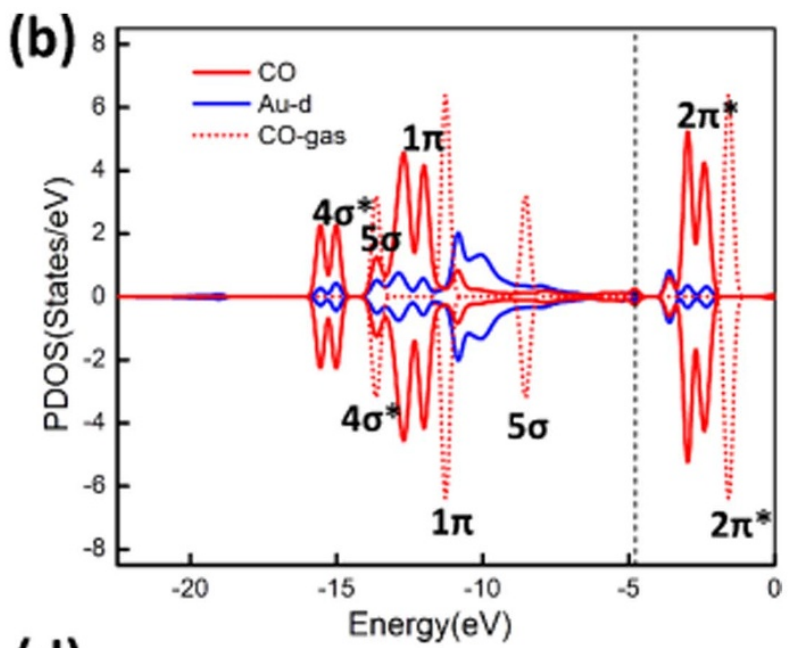

(d)

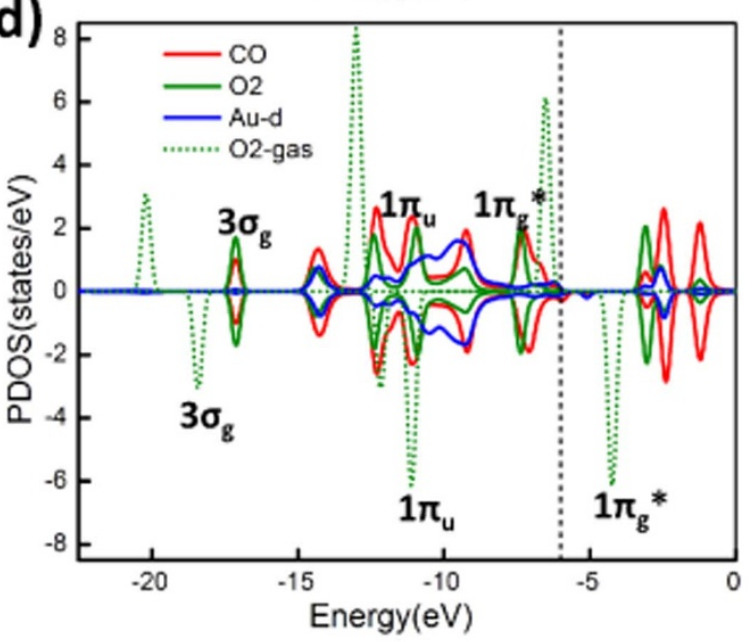

Figure 4 Electronic structure analysis of $\mathrm{CO}$ oxidation on Au-embedded $\boldsymbol{h}$-BN monolayer. a) The profile distributions of $\mathrm{O}_{2}$ 's LUMO and $\mathrm{HOS}$ of $\mathrm{CO}$ coadsorbed $\mathrm{Au} / \mathrm{V}_{\mathrm{B}}-h$-BN. The isosurface value is 0.25 . b) to d) are the PDOS profiles for CO coadsorbed Au/ $\mathrm{V}_{\mathrm{B}}-h$-BN, TS2-II, and MS structures, respectively. The red and green dotted lines denoted the DOS of free $\mathrm{O}_{2}$ or CO molecules, respectively. The Fermi energy level is plotted with black dotted line.

Information). Instead of dissociation into $\mathrm{CO}_{2}$ molecule and $\mathrm{O}$ atom with a high energy barrier $(0.72 \mathrm{eV})$, the formed OCOO (MS-I in Figure 2b) may react with the second $\mathrm{CO}$ molecule to form OOCAuCOO intermediate (MS-II) again with a relative low energy barrier of $0.23 \mathrm{eV}$. The rate-limit step in PATH-III is still the dissociation of OOCAuCOO into two $\mathrm{CO}_{2}$ molecules, as that in PATHTER, whereas more reaction steps and higher energy barrier for $\mathrm{O}_{2}$ activation are required in PATH-III than those in PATH-TER. Note that the CO oxidation via neither PATH-BLH nor PATH-III has not been observed in our BOMD simulations.

The $\mathrm{CO}$ promoted $\mathrm{O}_{2}$ activation and synchronous generation of two $\mathrm{CO}_{2}$ molecules present a new tri-molecular $\mathrm{E}-\mathrm{R}$ reaction for $\mathrm{CO}$ oxidation on supported Au atom, which has not been reported previously. This kind of $\mathrm{CO}$ promoted $\mathrm{O}_{2}$ activation on $\mathrm{Au} / \mathrm{V}_{\mathrm{B}}-h-\mathrm{BN}$ can be understood with the frontier molecular orbitals involved in the reaction between $\mathrm{O}_{2}$ and co-adsorbed $\mathrm{CO}$ molecules. It has been well known that the $\mathrm{O}_{2}$ activation is accomplished by injecting extra electrons in the lowest unoccupied anti-bonding state $\left(\pi^{*}{ }_{2 \mathrm{p}}\right)$, i.e. the lowest unoccupied molecular orbital (LUMO) of $\mathrm{O}_{2}$ molecule. As shown in Figure 4a, the symmetric match between the LUMO of $\mathrm{O}_{2}$ molecule and the highest occupies states (HOS) of CO coadsorbed on $\mathrm{Au} / \mathrm{V}_{\mathrm{B}}-h-\mathrm{BN}$ promotes the $\mathrm{O}_{2}$ activation. To further explain the interaction between $\mathrm{CO}, \mathrm{O}_{2}$ and $\mathrm{Au} / \mathrm{V}_{\mathrm{B}}-h-\mathrm{BN}$, we plotted the partial density of states (PDOS) of $\mathrm{CO}$ co-adsorbed $\mathrm{Au} / \mathrm{V}_{\mathrm{B}}-h-\mathrm{BN}$, the TS2-II and MS-II structures in Figure $4 \mathrm{~b}, 4 \mathrm{c}$, and $4 \mathrm{~d}$. The DOS of free $\mathrm{CO}$ and $\mathrm{O}_{2}$ molecules are plotted in dotted line for comparison. As shown in Figure $4 \mathrm{~b}$, the $\mathrm{CO}$ adsorption on $\mathrm{Au}$ atom mainly originates from the interaction between Au's 3d orbital and CO's $5 \sigma$ and $2 \pi^{*}$ orbitals. At TS2-II structure (Figure $4 \mathrm{c}$ ), a small amount of charge is transferred to $\mathrm{O}_{2}$ 's $\pi^{*} 2 \mathrm{p}$ orbital, which can be identified from $\mathrm{O}_{2}$ 's PDOS contribution at the Fermi energy level in Figure 4c. It is clear that $\mathrm{O}_{2}$ 's $\pi^{*} 2 \mathrm{p}$ state is fully occupied for the major spin, while that for the minor spin is splitted and partially occupied. In the MS-II state, strongly hybridized states between co-adsorbed CO and $\mathrm{O}_{2}$ molecules can be found just below the Fermi energy level, as shown in Figure 4d. The highest occupied states (HOS) and the lowest unoccupied states (LUS) of MS-II state are shown in Figure S5.

At last, the $\mathrm{CO}$ oxidation on $\mathrm{Au}$ dimer supported by $h$-BN monolayer with $\mathrm{B}$ vacancy, i.e. $\mathrm{Au}_{2} / \mathrm{V}_{\mathrm{B}}-h-\mathrm{BN}$, was also examined. The adsorption structures and energies are summarized in Figure S6 (See Supporting Information). Au dimer is trapped in the vacancy with a tilted $\mathrm{Au}-\mathrm{Au}$ bond to the $h$-BN monolayer surface and the average adsorption energy is $2.53 \mathrm{eV}$ per $\mathrm{Au}$ atom. This value is remarkably smaller than that of a single Au atom, indicating a well distribution of $\mathrm{Au}$ atom on the defective $h$-BN monolayer. Up to three $\mathrm{CO}$ molecules can be adsorbed on $\mathrm{Au}_{2}$ with one on the $\mathrm{Au}$ atom at the vacancy $(\mathrm{Au}-1)$ and two molecules on the other $\mathrm{Au}$ atom (Au2 ). The calculated adsorption energies for three $\mathrm{CO}$ molecules are $1.30,1.11$, and $0.25 \mathrm{eV}$ in sequence. Figure 5 illustrates the reaction pathway for $\mathrm{CO}$ oxidation. The $\mathrm{O}_{2}$ molecule reacts with the $\mathrm{CO}$ 
TS1

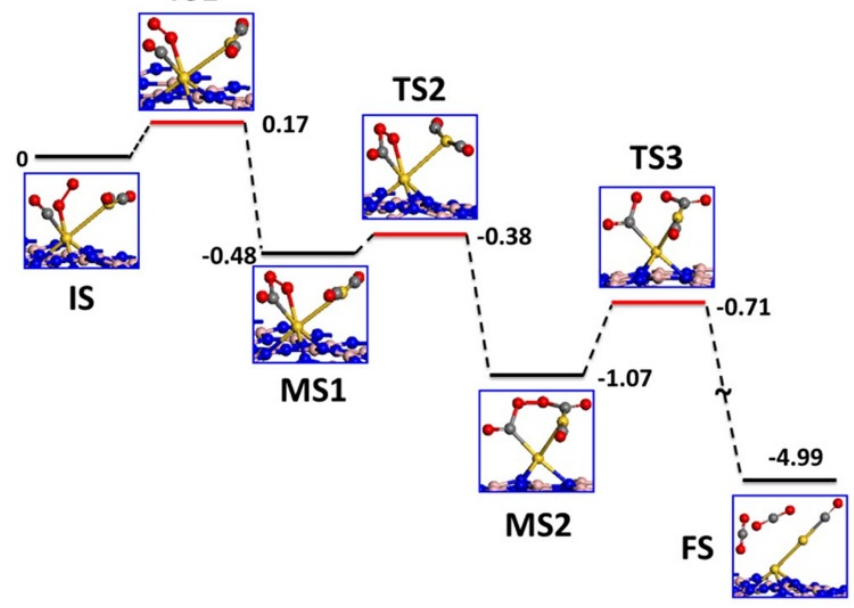

Figure $5 \mid \mathrm{CO}$ oxidation on $\mathrm{Au}_{2}$-embedded $\boldsymbol{h}$-BN monolayer. Reaction pathway for $\mathrm{CO}$ oxidation on $\mathrm{Au}_{2} / \mathrm{V}_{\mathrm{B}}-\mathrm{h}-\mathrm{BN}$. The energy given in figures is the energy relative to initial state.

molecule on Au-1 atom, forming an intermediate OCOO structure with the energy barrier of $0.17 \mathrm{eV}$ at the first step. Next, the OCOO intermediate reacts with one $\mathrm{CO}$ molecule on $\mathrm{Au}-2$ and forms OCOOCO ring structure with an energy barrier of $0.10 \mathrm{eV}$. At the last step, the OCOOCO intermediate dissociates into two $\mathrm{CO}_{2}$ molecules with an energy barrier of $0.37 \mathrm{eV}$, which is $0.10 \mathrm{eV}$ lower than that on $\mathrm{Au} / \mathrm{V}_{\mathrm{B}}-h-\mathrm{BN}$.

In conclusion, the $\mathrm{CO}$ oxidation on single $\mathrm{Au}$ atom anchored to the $h$-BN monolayer with boron vacancy defect was examined by using first-principles calculations and quantum BOMD simulation. We found that $\mathrm{Au}$ atom on $\mathrm{N}$ vacancy will be displaced by gas $\mathrm{CO}$ and $\mathrm{O}_{2}$ molecule, while much stable on $\mathrm{B}$ vacancy. The $\mathrm{CO}$ oxidation on $\mathrm{Au}$ atom supported by $h$-BN monolayer with $\mathrm{B}$ vacancy prefers an unreported tri-molecular E-R mechanism, where $\mathrm{O}_{2}$ is activated by two adsorbed $\mathrm{CO}$ molecules with an energy barrier of $0.09 \mathrm{eV}$. The formed OOCAuCOO intermediate dissociates into two $\mathrm{CO}_{2}$ molecules synchronously, which is the rate-limiting step with an energy barrier of $0.47 \mathrm{eV}$. Compared with traditional bimolecular $\mathrm{L}-\mathrm{H}$ mechanism, trimolecular E-R mechanism largely demands lower reaction energy barrier. By using the micro-kinetic analysis, the $\mathrm{CO}$ oxidation following the tri-molecular E-R mechanism entails much higher reaction rate $\left(1.43 \times 10^{5} \mathrm{~s}^{-1}\right)$ than that of bimolecular L-H mechanism $\left(4.29 \mathrm{~s}^{-1}\right)$. The quantum BOMD simulations reproduce the whole reaction. Our results demonstrated a potential for $\mathrm{CO}$ oxidation on $h$-BN monolayer supported atomic gold.

\section{Methods}

All calculations are performed by using the linear combination of atomic orbital and spin-polarized density functional theory method, implemented in $\mathrm{DMol}^{3}$ package (DMol3 5.5 is a density functional theory quantum mechanical package available from Accelrys Software Inc.) ${ }^{59-60}$ The generalized gradient approximation with Perdew-Burke-Ernzerhof (PBE) functional form with effective core potential, and double numerical basis set with polarization function are adopted in the calculations $^{61-63}$. The real-space global cutoff radius is set to be $4.5 \AA$. A tetragonal supercell containing $6 \times 6$ unit cells of $h$-BN monolayer is used and the thickness of vacuum layer is chosen as $20.52 \AA$. Only $\Gamma$-kpoint is used to describe the Brillouin zone for geometric optimization and $6 \times 6 \times 1$ kpoint for electronic structures calculations ${ }^{64}$. The smearing parameter is set to be 0.001 Hartree. Test calculation indicates that the results don't change when the smearing parameter is set zero. The structures of TS are determined with synchronous transit methods and confirmed with frequency calculations. The constant temperature and constant volume quantum BOMD simulation is performed by using the Nosé-Hoover method, in which the kinetic energy fluctuation of the thermostat variable is controlled by coupling it to another thermostat variable and the temperature of the system is maintained at $300 \mathrm{~K}^{65,66}$. The time step is $1.0 \mathrm{fs}$ and the total simulation time is $5.0 \mathrm{ps}$. Note that the spin crossover effect is not considered in the calculation, however, the spin stats of reactants, transition states, intermediates, and products are fully examined to obtain the lowest energy structures. The $\mathrm{CO}$ oxidation rates are estimated by using the micro-kinetic analysis (See details in Method in Supporting Information).

1. Yang, X. F. et al. Single-Atom Catalysts: A new Frontier in heterogeneous catalysis. Accounts Chem. Research. 46, 1740 (2013).

2. Heiz, U., Sanchez, A., Abbet, S. \& Schnelder, W.-D. Catalytic oxidation of carbon monoxide on monodispersed platinum clusters: Each atom counts. J. Am. Chem. Soc. 121, 3214-3217 (1999).

3. Yulikov, M. et al. Binding of Single Gold Atoms on Thin $\mathrm{MgO}(001)$ Films. Phys. Rev. Lett. 96, 146804 (2006).

4. Sterrer, M. et al. When the Reporter Induces the Effect: Unusual IR spectra of CO on $\mathrm{Aul} / \mathrm{Mg}(001) / \mathrm{Mo}$ (001). Angew. Chem. Int. Ed. 45, 2633-2635 (2006).

5. Qiao, B. et al. Single-atom catalysis of CO oxidation using Pt1/FeOx. Nat. Chem. 3, 634-641 (2011)

6. Yin, H. J., Tang, H. J., Wang, D., Gao, Y. \& Tang, Z. Y. Facile Synthesis of Surfactant-Free Au Cluster/Graphene Hybrids for High-Performance Oxygen Reduction Reaction. ACS Nano 6, 8288-8297 (2012).

7. Novoselov, K. S. et al. Electric Field Effect in Atomically Thin Carbon Films. Science 306, 666 (2004).

8. Geim, A. K. \& Novoselov, K. S. The rise of graphene. Nat. Mater. 6, 183-191 (2007).

9. Scheuermann, G. M., Rumi, L., Steurer, P., Bannwarth, W. \& Mülhaupt, R. Palladium Nanoparticles on Graphite Oxide and Its Functionalized Graphene Derivatives as Highly Active Catalysts for the Suzuki-Miyaura Coupling Reaction. J. Am. Chem. Soc. 131, 8262-8270 (2009).

10. Zhang, N. et al. Fabrication of gold nanoparticle/graphene oxide nanocomposites and their excellent catalytic performance. J. Mater. Chem. 21, 11080-11083 (2011).

11. He, H. \& Gao, C. Graphene nanosheets decorated with Pd, Pt, Au, and Ag nanoparticles: Synthesis, characterization, and catalysis applications. Sci. China Chem. 54, 397-404 (2011).

12. Machado, B. F. \& Serp, P. Graphene-based materials for catalysis. Catal. Sci. Technol. 2, 54-75 (2012).

13. Li, Y. et al. Gold nanoparticles-graphene hybrids as active catalysts for Suzuki reaction. Mater. Res. Bull. 45, 1413-1418 (2010).

14. Zan, R., Bangert, U., Ramasse, Q. \& Novoselov, K. S. Metal-Graphene Interaction Studied via Atomic Resolution Scanning Transmission Electron Microscopy. Nano Lett. 11, 1087-1092 (2011).

15. Subrahmanyam, K. S., Manna, A. K., Pati, S. K. \& Rao, C. N. R. A study of graphene decorated with metal nanoparticles. Chem. Phys. Lett. 497, 70-75 (2010).

16. Liu, L. et al. The 2-D growth of gold on single-layer graphene $/ \mathrm{Ru}(0001)$ : Enhancement of CO adsorption. Surf. Sci. 605, L47-L45 (2011).

17. Liu, J., Fu, S., Yuan, B., Li, Y. \& Deng, Z. Toward a Universal “Adhesive Nanosheet" for the Assembly of Multiple Nanoparticles Based on a ProteinInduced Reduction/Decoration of Graphene Oxide. J. Am. Chem. Soc. 132, 7279-7281 (2010).

18. Tang, Z., Shen, S., Zhuang, J. \& Wang, X. Noble-Metal-Promoted ThreeDimensional Macroassembly of Single-Layered Graphene Oxide. Angew. Chem. Int. Ed. 49, 4603-4607 (2010).

19. Chen, G. et al. Improved Stability and Catalytic Properties of Au16 Cluster Supported on Graphane. J. Phys. Chem. C 115, 20168-20174 (2011).

20. Lu, Y. H., Zhou, M., Zhang, C. \& Feng, Y. P. Metal-Embedded Graphene: A Possible Catalyst with High Activity. J. Phys. Chem. C 113, 20156-20160 (2009).

21. Zhang, X. et al. Catalytically active single-atom niobium in graphitic layers. Nat. Comm. 4, 1924 (2013).

22. Li, Y. F., Zhou, Z., Yu, G. T., Chen, W. \& Chen, Z. F. CO Catalytic Oxidation on Iron-Embedded Graphene: Computational Quest for Low-Cost Nanocatalysts. J. Phys. Chem. C 114, 6250-6254 (2010).

23. Song, E. H., Wen, Z. \& Jiang, Q. CO Catalytic Oxidation on Copper-Embedded Graphene. J. Phys. Chem. C 115, 3678-3683 (2011).

24. Zhang, T. et al. Adsorption and Catalytic Activation of $\mathrm{O} 2$ Molecule on the Surface of Au-Doped Graphene under an External Electric Field. J. Phys. Chem. C 116, 19918-19924 (2012).

25. Sun, S. et al. Single atom Catalysis Using Pt/Graphene Achieved through atomic layer depositon. Sci. Rep. 3, 1775 (2013).

26. Tang, Y., Yang, Z. \& Dai, X. A theoretical simulation on the catalytic oxidation of CO on Pt/graphene. Phys. Chem. Chem. Phys. 14, 16566 (2012).

27. Novoselov, K. S. et al. Two-dimensional atomic crystals. Proc. Nat. Acad. Sci. 102, 10451-10453 (2005).

28. Song, L. et al. Large Scale Growth and Characterization of Atomic Hexagonal Boron Nitride Layers. Nano Lett. 10, 3209-3215 (2010).

29. Shi, Y. et al. Synthesis of Few-Layer Hexagonal Boron Nitride Thin Film by Chemical Vapor Deposition. Nano Lett. 10, 4134-4139 (2010).

30. Warner, J. H., Rümmeli, M. H., Bachmatiuk, A. \& Büchner, B. Atomic Resolution Imaging and Topography of Boron Nitride Sheets Produced by Chemical Exfoliation. ACS Nano 4, 1299-1304 (2010).

31. Zhi, C. Y., Bando, Y., Tang, C. C., Kuwahara, H. \& Golberg, D. Large-Scale Fabrication of Boron Nitride Nanosheets and Their Utilization in Polymeric Composites with Improved Thermal and Mechanical Properties. Adv. Mater. 21, 2889-2893 (2009). 
32. Jin, C. H., Lin, F., Suenaga, K. \& Iijima, S. Fabrication of a Freestanding Boron Nitride Single Layer and Its Defect Assignments. Phys. Rev. Lett. 102, 195505 (2009).

33. Du, A. J. et al. Dots versus Antidots: Computational Exploration of Structure, Magnetism, and Half-Metallicity in Boron-Nitride Nanostructures. J. Am. Chem. Soc. 131, 17354-17359(2009).

34. Zhao, P., Su, Y., Zhang, Y., Li, S.-J. \& Chen, G. CO catalytic oxidation on ironembedded hexagonal boron nitride sheet. Chem. Phys. Lett. 515, 159-162 (2011).

35. Gao, M., Lyalin, A. \& Taketsugu, T. Catalytic Activity of $\mathrm{Au}$ and $\mathrm{Au}_{2}$ on the $h-\mathrm{BN}$ Surface: Adsorption and Activation of $\mathrm{O}_{2}$. J. Phys. Chem. C 116, 9054-9062 (2012).

36. Gao, M., Lyalin, A. \& Taketsugu, T. CO oxidation on $h$-BN supported Au atom. J. Chem. Phys. 138, 034701 (2013).

37. Haruta, M., Kobayashi, T., Samo, H. \& Yamada, N. Novel Gold Catalysts for the Oxidation of Carbon Monoxide at a Temperature far Below $0{ }^{\circ}$ C. Chem. Lett. 2 , 405-408 (1987).

38. Haruta, M., Yamada, N., Kobayashi, T. \& Iijima, S. Gold Catalysts Prepared by Coprecipitation for Low-Temperature Oxidation of Hydrogen and of Carbon Monoxide. J. Catal. 115, 301-309 (1989)

39. Valden, M., Lai, X. \& Goodman, D. W. Onset of Catalytic Activity of Gold Clusters on Titania with the Appearance of Nonmetallic Properties. Science 281, 1647-1650 (1998).

40. Chen, M. S. \& Goodman, D. W. The Structure of Catalytically Active Gold on Titania. Science 306, 252-255 (2004)

41. Fu, Q., Saltsburg, H. \& Flytzani-Stephhanopoulos, M. Active Nonmetallic Au and Pt Species on Ceria-Based Water-Gas Shift Catalysts. Science 301, 935-938 (2003).

42. Herzing, A. A., Kiely, C. J., Carley, A. F., Landon, P. \& Hutchings, G. J. Identification of Active Gold Nanoclusters on Iron Oxide Supports for CO Oxidation. Science 321, 1331-1335 (2008).

43. Yoon, B. et al. Charging Effects on Bonding and Catalyzed Oxidation of CO on $\mathrm{Au}_{8}$ Clusters on MgO. Science 307, 403-407 (2005).

44. Risse, T. et al. Acc. Chem. Res. 41, 949 (2008)

45. Landman, U. et al. Factors in gold nanocatalysis: oxidation of CO in the nonscalable size regime. Top. Catal. 44, 145-158 (2007).

46. Haruta, M. Size- and support-dependency in the catalysis of gold. Catal. Today $\mathbf{3 6}$, 153-166 (1997).

47. Sanchez, A. et al. When Gold Is Not Noble: Nanoscale Gold Catalysts. J. Phys. Chem. A. 103, 9573-9578 (1999)

48. Chen, M., Cai, Y., Yan, Z. \& Goodman, D. W. On the Origin of the Unique Properties of Supported Au Nanoparticles. J. Am. Chem. Soc. 128, 6341-6346 (2006).

49. Bürgel, C. et al. Influence of Charge State on the Mechanism of CO Oxidation on Gold Clusters. J. Am. Chem. Soc. 130, 1694-1698 (2008).

50. Grunwaldt, J.-D. \& Baiker, A. Gold/Titania Interfaces and Their Role in Carbon Monoxide Oxidation. J. Phys. Chem. B. 103, 1002-1012 (1999).

51. Li, L. et al. CO Oxidation on $\mathrm{TiO}_{2}(110)$ supported Subnanometer Gold Clusters: Size and Shape Effects. J. Am. Chem. Soc. 135, 19336-19346 (2013).

52. Yoon, B., Häkkinen, H. \& Landman, U. Interaction of $\mathrm{O}_{2}$ with Gold Clusters: Molecular and Dissociative Adsorption. J. Phys. Chem. A. 107, 4066-4071 (2003).

53. Häkkinen, H. \& Landman, U. Gas-Phase Catalytic Oxidation of CO by $\mathrm{Au}^{2-}$. J. Am. Chem. Soc. 123, 9704-9705 (2001).

54. Kimble, M. L., Castleman, A. W., Mitrić, R., Bügel, C. \& Bonačić-Koutecky, V. Reactivity of Atomic Gold Anions toward Oxygen and the Oxidation of CO: Experiment and Theory. J. Am. Chem. Soc. 126, 2526-2535 (2004).

55. Chen, M. \& Goodman, D. W. Catalytically Active Gold: From Nanoparticles to Ultrathin Films. Acc. Chem. Res. 39, 739-746 (2006).

56. Liu, C. Y. et al. CO Self-Promoting Oxidation on Nanosized Gold Clusters: Triangular $\mathrm{Au}_{3}$ Active Site and CO Induced O-O Scission. J. Am. Chem. Soc. 135 2583-2595 (2013).
57. Kittel, C. Introduction to Solid State Physics (Wiley, New York, 1968)

58. Behler, J., Delley, B., Lorenz, S., Reuter, K. \& Scheffler, M. Dissociation of $\mathrm{O}_{2}$ at $\mathrm{Al}(111)$ : The Role of Spin Selection Rules. Phys. Rev. Lett. 94, 036104 (2005).

59. Delley, B. An allelectron numerical method for solving the local density functional for polyatomic molecules. J. Chem. Phys. 92, 508-517 (1990).

60. Delley, B. From molecules to solids with the $\mathrm{DMol}^{3}$ approach. J. Chem. Phys. 113, 7756-7764 (2003).

61. Perdew, J. P., Burke, K. \& Ernzerhof, M. Generalized Gradient Approximation Made Simple. Phys. Rev. Lett. 77, 3865-3868 (1996).

62. Dolg, M., Wedig, U., Stoll, H. \& Preuss, H. Energy-adjusted ab initio pseudopotentials for the first row transition elements. J. Chem. Phys. 86, 866 (1987).

63. Douglas, M. \& Kroll, N. M. Quantum electrodynamical corrections to the fine structure of helium. Ann. Phys. (San Diego) 82, 89-155 (1974).

64. Monkhorst, H. J. \& Pack, J. D. Special points for Brillouin-zone integrations. Phys. Rev. B 13, 5188-5192 (1976).

65. Tuckerman, M. E., Liu, Y., Ciccotti, G. \& Martyna, G. J. Non-Hamiltonian molecular dynamics: Generalizing Hamiltonian phase space principles to nonHamiltonian systems. J. Chem. Phys. 115, 1678-1702 (2001).

66. Nosé, S. A. A molecular dynamics method for simulations in the canonical ensemble. Mol. Phys. 52, 255 (1984).

\section{Acknowledgments}

This work was supported by grants from NKBRPC (Grant No. 2011CB921400, 2012CB922001), NSFC (Grant No. 51172223, 21121003, 21103156, 21233007), Strategic Priority Research Program of CAS (XDB01020300), One-Hundred Talent Project of CAS, the Fundamental Research Funds for the Central Universities (WK2060190025, WK2060140014), the National Program for Support of Top-notch Young Professionals, Shanghai-SCC, USTC-SCC and CAS-SCC. X.C.Z. is also supported by grants from ARL (W911NF1020099) and from USTC for (1000 Talents Program) Qianren-B summer research.

\section{Author contributions}

X.W. developed the main idea and supervised the project. K.M. and W.Z. performed electronic and reaction calculations. L.L. performed the micro-kinetic analysis. K.M., W.Z. and X.W. performed the data analysis and wrote the paper. X.Z. and J.Y. edited the paper. Discussions have been conducted within X.W., W.Z., K.M., L.L., Y.P., X.Z. and J.Y.

\section{Additional information}

Supplementary information accompanies this paper at http://www.nature.com/ scientificreports

Competing financial interests: The authors declare no competing financial interests. How to cite this article: Mao, K. et al. A Theoretical Study of Single-Atom Catalysis of CO Oxidation Using Au Embedded 2D $h$-BN Monolayer: A CO-Promoted $\mathrm{O}_{2}$ Activation. Sci. Rep. 4, 5441; DOI:10.1038/srep05441 (2014).

This work is licensed under a Creative Commons Attribution-NonCommercialNoDerivs 4.0 International License. The images or other third party material in this article are included in the article's Creative Commons license, unless indicated otherwise in the credit line; if the material is not included under the Creative Commons license, users will need to obtain permission from the license holder in order to reproduce the material. To view a copy of this license, visit http:// creativecommons.org/licenses/by-nc-nd/4.0/ 